\title{
Anti-Windup PID Controller by ITAE Tuning Rule for Steam Distillation System
}

\author{
Muhd Azri Abdul Razak, Haslizamri Md.Shariff \\ Faculty Of Electrical Engineering, Universiti Teknologi MARA Terengganu Malaysia
}

\begin{abstract}
In control engineering system, the PID controller is more prefer compared to the other controller. It very simple and easy to develop. Unfortunately, PID controller exhibit a weakness once spike at wind-up region. The wind-up problem is always happen due to inability of compensator to control the phenomenon. The main cause is created in controller design phase; neglect a nonlinearities dynamic. The issue can be solved by implementation of additional integral feedback compensation in order to minimize the effect of windup situation. The wind-up phenomenon can cause high overshoot, long settling time and loss productivity yield. This objective of this research to improve windup situation using backcomputation method tuning by Integral Time Absolute Error (ITAE) tuning rule. The propose ITAEProportional-Integral-Derivative integrated AntiWindup (ITAE-PID-AW) controllers revealed better performances compared to the ITAE-ProportionalIntegral-Derivative (ITAE-PID) controller.
\end{abstract}

Keywords:- $\quad$ Integral-Time-Absolute-Error-(ITAE), Proportional Integral Derivatives (PID), ProportionalIntegral Derivatives integrated Anti-Windup (PID-AW), Small-Medium Scale Steam Distillation System (SSSDS).

\section{INTRODUCTION}

PID compensator are widely applied in industrial processes from 1930 until today because simple structure and easy to tune, efficient for linear dynamic process and most of engineer prefer to utilize in any control system [1], [2]. Currently, hundred tuning rule were designed for linear and nonlinear systems to achieve high efficiency of production process. [3]. The Ziegler-Nichols, Cohen-Coon, Chen-Hrones-Reswick and Tyreus-Luyben tuning rules already established long time ago and famous among the practitioners. However, each tuning rule does not fit and perform for all system dynamic. And, nobody was claim which tuning rule capable to obtain optimum efficiency. Means, engineer need to study before utilized any tuning rule which is suitable or not for their system in production plant.

Although the PID was established a hundred year ago, some weakness has been detected when behavior of the system presence nonlinearities dynamic; the windup phenomenon will attack a running system. The root of these problem due to limitation capacity of system actuator or input controller to unwind the dynamic phenomenon.
To more detail, windup phenomenon is occur when one of the controller element; which is integral action from controller itself spike until maximum operation level and controller feedback does not affect anymore [4]. Consequently, the controller output start to increase; which is integral action nonstop integrate and accumulate without realize that system running in error condition. The integrator action continuously integrate and increase the value in a system dynamic operation and its produced undesired error controller signal which are beyond the operating region of the actuator operation [5]. Consequently, at the stage the feedback loop unfunction and actuator integrate the undesired value [6]. The system feedback loop loss-functionality anymore and exhibit highovershoot, settling time longer time taken and dynamic system operation become unstable [6]-[8].

To avoid windup phenomenon in control system, engineer should design additional feedback in PID controller structure to overcome the problem in a system. The classical PID controller unable to capture nonlinearities behavior produce by a system dynamic.

Based on the literature, the PID controller are utililzed widely in steam distillation system. Unfortunately, only few number of enginner and practitioner develop the PID embedded with anti wind up strategy [9]-[11]. Until today, the processto control of steam distillation column only design PID base controller and ignore unwanted windup phenomena [7], [11]. Generally, the basic structure of PID controller has some problem which incapable to control windup phenomenon [7]. The important of intelligent controller development is to control temperature in steam distillation column. If the raw material extract from the column expose to high degree of temperature, another issue will raise: degradation of the extracted essential oils.

The unwanted windup phenomenon could be solved by implementation of PID integrated Anti Windup (PIDAW) controller. This research reveal a method to overcome windup phenomenon problem using PID integrated AntiWindup (PID-AW) controller tuned by Integral Time Absolute Error (ITAE) method. The function of antiwindup action integrated in classical PID structure is to minimize bad effect of control input nonlinearities in close loop system performance [12]. 


\section{PID AND PID INTEGRATED ANTI-WINDUP STRUCTURES}

Generally, the fundamental PID structure consist of "three terms" controller which; Proportional (P) action, Integral (I) action and Derivative (D) action. The Figure 1 show the PID controller block diagram.

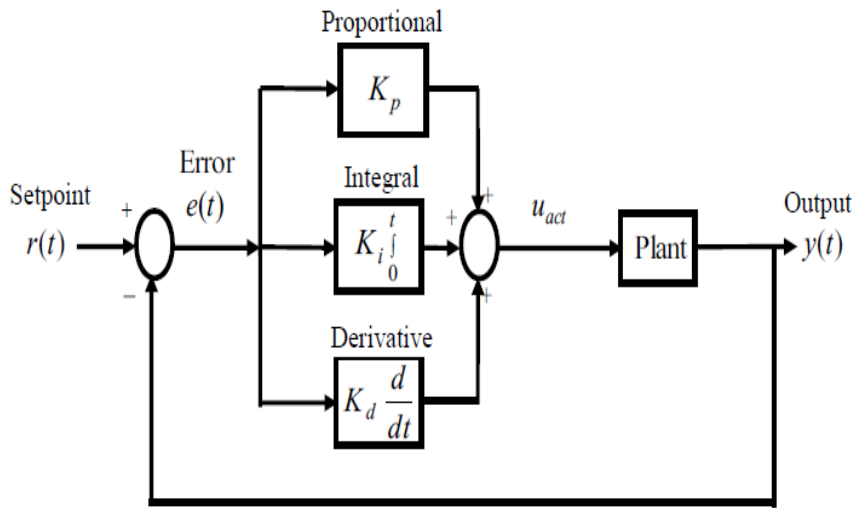

Fig 1:- The Block Diagram of PID structure

The tuning of ITAE rule is describe in [13]. The element of Integral of Time is multiplied by Absolute Error (ITAE) Criterion is given by

$I_{I T A E}=\int_{0}^{T} t|e(t)| d t$

Which the time of $t$ and $e(t)$ are total of errors where its calculated as a difference between the system set point versus system output [13].

$K_{p}=\frac{0.965}{K\left(\frac{T}{L}\right)^{0.855}}$

Time Contsant for Integral action formula is

$$
T_{i}=\frac{T}{0.796-0.147 \frac{L}{T}}
$$

The Time Constant for Derivative action calculation is

$T_{d}=0.308 T\left(\frac{L}{T}\right)^{0.929}$

The development of classical ITAE-PID controller as compared to ITAE-PID integrated Anti-Windup (ITAEPIDAW) formulation can be shown by adjustments of extra feedback $\left(1 / T_{a}\right)$ integrated in ITAE-PID-AW as in Figure 2 [6].

The extra feedback loop integrate into ITAE-PID-AW has error computability between saturated input signal value and unsaturated/actual input signal value, $u_{\text {act }}$.

The theory of windup situation attack a system when actual control input penetrate beyond the saturated region, and the new integrator will process the error information between values of saturated signal versus actual signal via $1 / T_{a}$ gain. After error information received; the new integral action value will be processed and computed within the limit of the system.

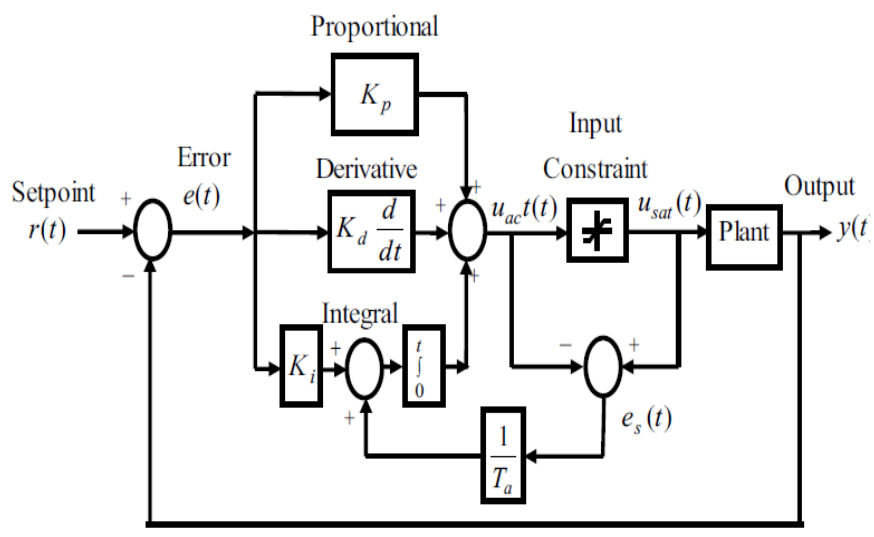

Fig 2:- Block Diagram of PID Integrated Anti-Windup (PID-AW) Structure

The tuning of $T_{a}$ value has significant effect in performance and efficiency of control system [7]. The response new integrator feedback able to return to origin at desired setpoint is depend on $T_{a}[6]$.

To study the performance of the system is optimized, the $T_{a} T_{a}$ value are proposed in three condition. Initially, $T_{a}$ value is based on Astrom and Hagglund [6], [14] proposed

$T_{a}=\sqrt{T_{i} T_{d}}$

(5)

The determination of second and third $T_{a}$ value are based on Ioannou suggested [15], where the $T_{a}$ should in the range of

$T_{i} \geq T_{a} \geq T_{d}$

(6)

In order to optimize the system performance, the $T_{a}$ values are selected at the lowest and highest range of (6)

$T_{a}=T_{d}$

(7)

And, the third $T_{a}$ value is

$T_{a}=T_{i}$

(8)

The selection of three $T_{a}$ values will be tested to all PID-AW controllers. The system will be simulated with four developed controller which. The system will controlled by PID and also controlled PID-AW using difference three parameters of $T_{a}$. 


\section{SIMULATION RESULTS}

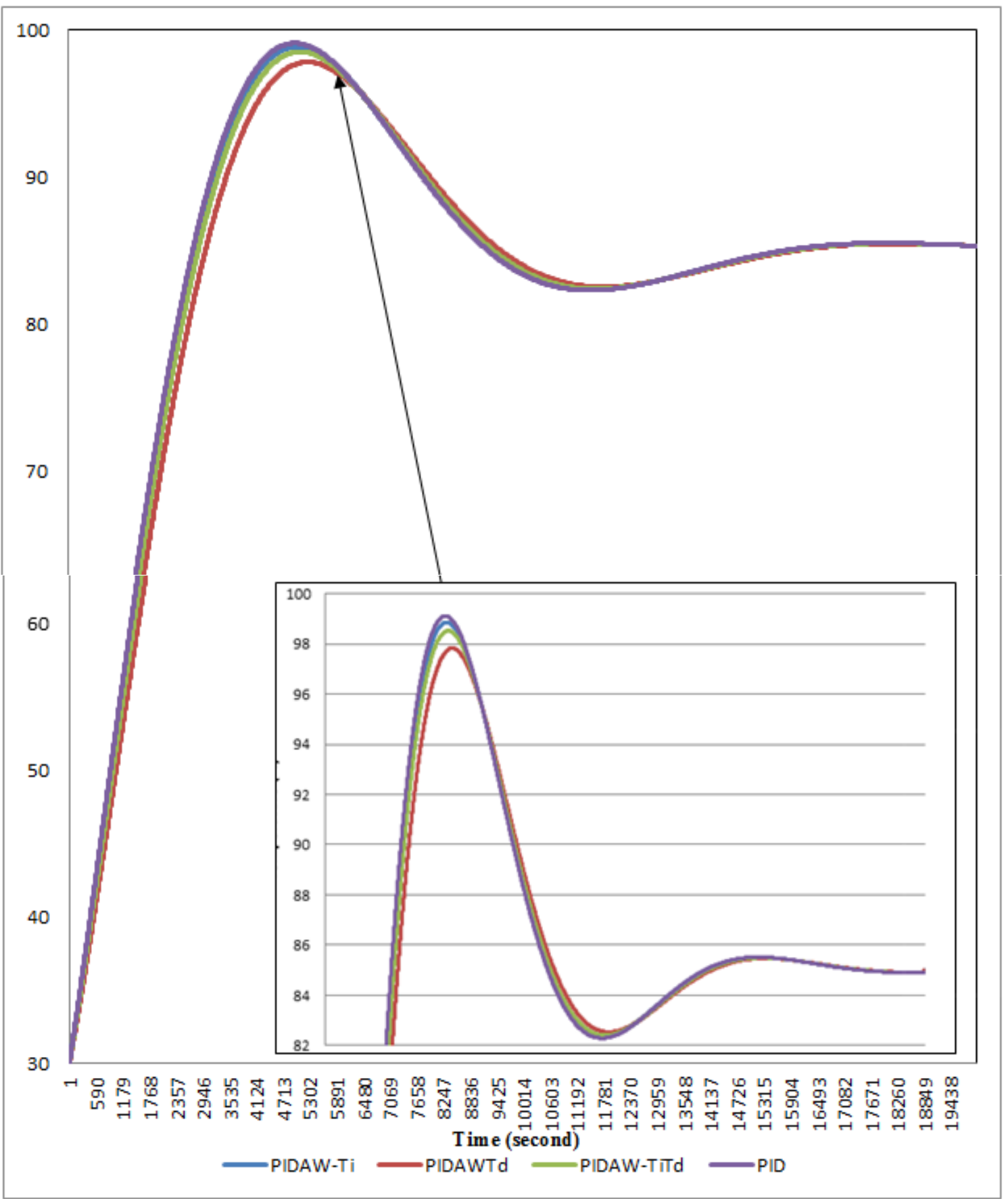

Fig 3:- The Simulated Output Response by Step Input; PID, PID-AW-Ti, PID-AW-Td and PID-AW-TiTd Controllers.

\begin{tabular}{|c|c|c|c|c|}
\hline Performance Index & PID & PID-AW-TiTd & PID-AW-Ti & PID-AW-Td $^{\#}$ \\
\hline Overshoot, OS (\%) & 16.735 & 15.9097 & 16.3059 & $15.0882^{*}$ \\
\hline Settling Time (Ts) & 14295.00 & 14265.00 & 14233.00 & $14222.00^{*}$ \\
\hline Rise Time (Tr) & $2944.70 *$ & 3071.80 & 2999.30 & 3251.60 \\
\hline I-A-E & 56110 & 55960 & 56050 & $55760 *$ \\
\hline I-S-E & 144300 & 142500 & 143500 & $140200^{*}$ \\
\hline I-T-A-E & $1.453 \times 10^{9}$ & $1.450 \times 10^{9}$ & $1.452 \times 10^{9}$ & $1.444 \times 10^{*}$ \\
\hline
\end{tabular}

*preferred response by criteria/ \#preferred controller

Table 1:- Data for Controllers Performance in Step Test Based 
The Figure 3 show the response of simulated system output based on four controller developed using difference parameters. By empirical studied, all the PID-AW have shown good performance in overshoot which lower than PID output response.

The Table 1 show the performance achieved for each controller. The overshoot performance showed PID-AW controller using $T_{a}=T_{d}$ is outperformed the other controller. The settling time also recoreded fastest among the controllers.

The error performance indexes; I-A-E, I-S-E and I-TA-E also showed lesser than others controller. Means, the utilizing of $T_{a}=T_{d}$ as Tracking Time Constant for PIDAW is able to optimize the control system performance.

\begin{tabular}{|c|c|c|c|c|}
\hline Controller Name & Temperature $\left({ }^{\circ} \mathrm{C}\right)$ & Overshoot $(\%)$ & $\begin{array}{c}\text { Rise Time, } \mathbf{T r} \\
(\mathrm{sec})\end{array}$ & Settling Time, Ts (sec) \\
\hline \multirow{3}{*}{ PID } & $55^{\circ} \mathrm{C}$ & 11.9633 & $3095.90 *$ & 13761.00 \\
\hline & $7^{\circ} \mathrm{C}$ & 5.7781 & $2105.00 *$ & 14128.00 \\
\hline & $85^{\circ} \mathrm{C}$ & 4.748 & $2081.10^{*}$ & 13616.00 \\
\hline \multirow{3}{*}{ PID-AW-TiTd } & $55^{\circ} \mathrm{C}$ & 11.5586 & 3217.20 & 13763.00 \\
\hline & $7^{\circ} \mathrm{C}$ & 4.5261 & 2699.20 & 14665.00 \\
\hline & $85^{\circ} \mathrm{C}$ & 3.9085 & 2661.90 & 13124.00 \\
\hline \multirow{3}{*}{ PID-AW-Ti } & $55^{\circ} \mathrm{C}$ & 11.79 & 3145.40 & 13762.00 \\
\hline & $7^{\circ} \mathrm{C}$ & 5.11 & 2364.80 & 14321.00 \\
\hline & $85^{\circ} \mathrm{C}$ & 4.27 & 2339.20 & 13485.00 \\
\hline \multirow{3}{*}{ PID-AW-Td\# } & $55^{\circ} \mathrm{C}$ & $11.1005^{*}$ & 3393.40 & $13760.00 *$ \\
\hline & $70^{\circ} \mathrm{C}$ & $4.4249 *$ & 2784.90 & $14109.00 *$ \\
\hline & $85^{\circ} \mathrm{C}$ & $4.1259 *$ & 2671.30 & $11447.00 *$ \\
\hline
\end{tabular}

* preferred response by criteria/ \#preferred controller

Table 2:- Controller Performance: PID, PID-AW-Ti, PID-AW-Td and PID-AW-TiTd for Set Point Change Simulation Based.

In Table 2 reveal the test of Set Point Change which reveal the capability of the controllers in recovering the set point after a certain condition time. The simulated result showed the PID-AW tuned by $T_{a}=T_{d}$ contribute best overshoot and settling time. The lowest overshoot response and settling time are important to these process to ensure the raw material is not expose to high degree of temperature and might degradation quality of essential oils.

\section{CONCLUSION}

The experimental by simulation based revealed significant improvement achieved by PID-AW controller tuned by $T_{a}=T_{d}$ parameter. The OS and Ts responses exhibit lowest compared to other compensators.

The anti-windup system controlled by PID can be optimized utilized any parameters introduced in equations (5), (7) and (8). However, its depend on system behavior which tuning is able to produce best performance. An engineer need to test by heuristic tuning using parameters given.

\section{REFERENCES}

[1]. W. Upaphai, P. Bunyawanichakul, and M. Janthong, "Design of Self-tuning Fuzzy PID Controllers for Position Tracking Control of Autonomous Agricultural Tractor," Pertanika J., vol. 27, no. 1, pp. 263-280, 2019.

[2]. K. J. Astrom and R. M. Murray, Feedback Systems. PRINCETON UNIVERSITY PRESS PRINCETON AND OXFORD, 2012.

[3]. S. Galeani, S. Tarbouriech, M. Turner, and L. Zaccarian, "A Tutorial on Modern Anti-windup Design," Eur. J. Control, vol. 15, no. 3-4, pp. 418440, 2009.

[4]. Karl Johan Astrom, Feedback Systems. PRINCETON UNIVERSITY PRESS PRINCETON AND OXFORD, 2002.

[5]. R. Lucian, C. C. Rodolfo, C. C. Rodolfo, and J. E. Normey-rico, "Analysis of Anti-windup Techniques in PID Control of Processes with Measurement Noise," Elsevier Sci., vol. 51, no. 4, pp. 948-953, 2018. 
[6]. P. Kheirkhahan and E. Engineering, "Robust AntiWindup Control Design for PID Controllers," in 2017 17th International Conference on Control, Automation and Systems, 2017, no. Iccas, pp. 1622 1627.

[7]. P. Liu, P. Yan, S. Member, and Z. Zhang, "Robust Anti-Windup Compensation for High Precision Tracking of a Piezoelectric Nano-Stage," IEEE Trans. Ind. Electron., vol. 0046, no. c, 2016.

[8]. H. Jigang, W. Jie, and F. Hui, "An anti-windup selftuning fuzzy PID controller for speed control of brushless DC motor," Automatika, vol. 58, no. 3, pp. 321-335, 2018.

[9]. E. F. Mulder, P. Y. Tiwari, and M. V Kothare, "Simultaneous linear and anti-windup controller synthesis using multiobjective," Automatica, vol. 45, no. 3, pp. 805-811, 2009.

[10]. K. H. Raut, "A Study on Performance of Different PID Tuning Techniques."

[11]. J. Astrom and T. Hagglund, PID Controllers:Theory, Design and tuning, 2nd ed.: Instrument Society of America (ISA). 1995.

[12]. P. A. Ioannou and P. V. Kokotovic, "Instability analysis and improvement of robustness of adaptive control," Automatica, vol. 20, pp. 583-594, 1984. 